\title{
Oncogeriatrics (part 7.) \\ Geriatric assessment for older patients with cancer
}

\author{
Jakub Kenig, Kinga Szabat
}

Department of General, Oncological and Geriatric Surgery, Jagiellonian University Medical College, Krakow, Poland

The geriatric assessment (GA) is defined as a multidimensional, interdisciplinary diagnostic process focusing on determining an older person's medical, psychosocial, and functional capabilities that are not identified by routine evaluation. There is more and more data on the benefits of the GA in the evaluation and management process of older patients with cancer. It allows for the development of an individual cancer treatment plan resulting in less postoperative complications, reduced treatment toxicity, improved quality of life and very often without compromising survival. However, the relationship between specific domains of the GA and post-treatment medical outcomes, functional status and quality of life remains unknown. Moreover, there is still no consensus over what the "golden standard" GA should look like, which tools should be included and what cut-off should be used. This is still an active area of research. However, there is no doubt that understanding the health status of an older patient with cancer should be as important as cancer staging and tumour biology.

Key words: older patients, elderly, comprehensive geriatric assessment, frailty

As has been mentioned in the previous articles, older adults are a heterogeneous group having varying degrees of comorbidities, functional reserves, cognitive impairments and social support [1]. Therefore, chronological age alone and the routine format of medical history, physical examination, biochemistry and imaging tests often do not provide adequate information needed for optimal and tailored treatment. Many older adults have unidentified, uncommunicated, and therefore unaddressed aging-related conditions that are associated with morbidity and early mortality [2]. To help guide treatment decisions the geriatric assessment (GA) was introduced, a milestone in the field of geriatrics. Moreover, at present, cancer treatment for older patients is very often planned based on extrapolations of evidence derived from clinical trials in which younger patients or fit older patients enrolled [3].

The GA is defined as a multidimensional, interdisciplinary diagnostic process focusing on determining an older person's medical, psychosocial, and functional capabilities. In turn, the term comprehensive geriatric assessment (CGA) refers to a GA which also includes a plan for the further management of identified problems. Therefore, the main goal of the CGA in older cancer patients is to provide a comprehensive health appraisal to guide targeted interventions and appropriate cancer treatment selection [4].

The GA was initially developed and validated in the general older population for detecting vulnerability and aging-related issues that were associated with mortality [5]. However, numerous studies, though not all, have proved its usefulness equally in cancer patients:

- The GA allows the determination of a baseline health status, monitoring of changes and a diagnostic of the frailty status, which is an exponent of biological old age;

- The GA can identify age-related areas of vulnerability that can be missed in routine clinical evaluation in up to 50\% of patients [6]. These impairments concern physical functioning and nutritional status, but also very often geriatric

\section{How to cite:}

Kenig J, Szabat K. Oncogeriatrics (part 7.). Geriatric assessment for older patients with cancer. NOWOTWORY J Oncol 2020; 70: 153-157. 
syndromes such as: dementia, delirium, depression, incontinence, sarcopenia, osteoporosis/spontaneous fractures which are independent risk factors of worse outcome [6]. Routinely used oncological tools like the Eastern Cooperative Oncology Group (ECOG) or the Karnofsky performance status have been shown to poorly reflect functional impairment in older patients with cancer. In patients with an ECOG score $<2$ almost $40 \%$ of patients were dependent on some form of instrumental activities for daily living [7];

- Performing the GA can change treatment decisions for up to $50 \%$ of older patients $[8,9]$. In these studies, in the case of up to $28 \%$ of patients, the treatment was intensified and in case of up to $37 \%$, the treatment intensity was reduced $[10,11]$;

- The GA can identify areas for further rehabilitative actions such as: review of diet and nutrition, physical performance, psychological support, medication review and social support. In some studies, applying the GA reduced the number of treatment related complications. Other studies have not confirmed this, but in case of high-risk patients its use allowed the completion of the cancer treatment with fewer treatment modifications [12];

- The GA can predict survival of and adverse events during cancer treatment. Thus, it may assist clinical decision-making.

- The GA can improve patient physician communication about aging-related concerns and their influence on the treatment outcome [13]. A practical and convenient GA summary with recommendations for aging-sensitive interventions improves patient-cantered outcomes and patient satisfaction.

Biological age does not correspond with the chronological age. Therefore, it is difficult to arbitrarily set the level of age at which the GA should be implemented. Most of the guidelines recommend it at the age of 70 years. However, in our opinion, the age should be set at the level of 65 years in Polish society. It also should be performed in younger patients identified in screening tests [14].

The GA consists of several domains evaluating: functional status, mobility/falls, cognitive level, mood, comorbidity, poly- pharmacy, fatigue and social support. At present, there are several well-validated tools available. Table I presents an overview of the different tests with literature-based cut-offs that may be used in the GA process. There has been no consensus about which tools should be included in the GA and until now there have been no studies showing the superiority of one specific tool over another. Therefore, the choice of score might rely on local preferences, the aim of the tool and present resources.

The number of incorporated GA domains has a great influence on the diagnosis of frailty and on adequate risk assessment as we showed in one previous study. The summary deficit score based on the GA consisting of functional, mobility, cognitive, depression, nutritional, co-morbidity, polypharma$c y$, and social support questionnaires was the most accurate predictor of post-operative complications in comparison to models with less incorporated domains [33].

In turn, two large prospective studies - Cancer and Aging Research Group (CARG) and Chemiotherapy Risk Assessment Scale for High-Age Patients (CRASH) - identified which parameters of the GA were capable of predicting severe chemotherapy-related complications in a heterogeneous cancer population (tab. II) [33, 34]. Both scores revealed their superiority over the Karnofsky performance status or other classic oncological evaluation tools. They can also help determine the risks and benefits of treatment, promoting shared decision-making. High-risk patients can be monitored closely. A randomized study of GA-directed therapy for older patients with advanced lung cancer demonstrated reduced toxic effects of treatment and less treatment discontinuation in the GA group [35].

In case of radiotherapy the literature is still scarce. Spyropoulou et al. observed higher risk of not completing radiation in the case of impaired score on a VES-13 (screening frailty tool) [36].

There are various models of the GA. It can be performed within a geriatric ward with a specialized geriatric team. Six meta-analyses showed that this model is the most effective method with lower mortality, less institutionalization, and less functional decline compared with a standard ward [37-39]. In the case of the model with a specialized geriatric team that ap-

Table I. Glossary of the most common tools used in the geriatric assessment process

\begin{tabular}{|c|c|c|c|c|}
\hline Test & & Number of items & Range & Cut-off score \\
\hline $\begin{array}{l}\text { ADL (Katz Activities of Daily Living) } \\
\text { [15] }\end{array}$ & \multirow{4}{*}{$\begin{array}{l}\text { Functional } \\
\text { status }\end{array}$} & 6 & $0-6$ & $<5$ \\
\hline IADL (Lawton Instrumental Activities of Daily Living) [16] & & 8 & $0-8$ & $\leq 7$ \\
\hline $\begin{array}{l}\text { The Duke OARS Assessment of IADL } \\
\text { [17] }\end{array}$ & & 6 & 12 & $<9$ \\
\hline Barthel scale [18] & & 10 & $0-100$ & $\leq 60$ \\
\hline Self reported number of falls within different time frames & & 1 & $0-\infty$ & $\begin{array}{l}>2 \text { within last } 6 \\
\text { months }\end{array}$ \\
\hline $\begin{array}{l}\text { TUG (Timed Up and Go) } \\
\text { [19] }\end{array}$ & \multirow{2}{*}{$\begin{array}{l}\text { Physical } \\
\text { activity }\end{array}$} & 1 & $0-\infty$ & $\geq 15$ \\
\hline Gait speed [20] & & 1 & $0-\infty$ & \\
\hline
\end{tabular}




\begin{tabular}{|c|c|c|c|c|}
\hline Test & & Number of items & Range & Cut-off score \\
\hline Charlson Comorbidity Scale [21] & \multirow{2}{*}{ Comorbidity } & 19 & $0-37$ & $\geq 3$ \\
\hline Cumulative IIlness Rating Scale (CIRS-G) [22] & & 13 & $0-52$ & $>4$ \\
\hline Geriatric Depression Scale [23] & Depression & 15 & $0-15$ & $>5$ \\
\hline Mini-Mental State Examination [24] & \multirow{5}{*}{$\begin{array}{l}\text { Cognitive } \\
\text { function }\end{array}$} & 8 & $0-30$ & $<24$ \\
\hline Montreal Cognitive Assessment [25] & & 7 & $0-30$ & $<26$ \\
\hline Abbreviated mental test score AMTS (Hodgkinson) [26] & & 10 & $0-10$ & $\leq 6$ \\
\hline The Blessed Orientation-Memory-Concentration (BOMC) Test [27] & & 6 & $0-28$ & $>10$ \\
\hline Clock Drawing Test (CDT-test) [28] & & 7 & $0-7$ & $\leq 4$ \\
\hline Mini Nutritional Assessment [29] & \multirow{2}{*}{$\begin{array}{l}\text { Nutritional } \\
\text { assessment }\end{array}$} & 6 & $0-14$ & $<12$ \\
\hline MNA full [29] & & 18 & $0-30$ & $<24$ \\
\hline Number of medications & Toxicity risk & 1 & $0-\infty$ & $>4$ \\
\hline Brief Fatigue Inventory [30] & $\begin{array}{l}\text { Self- } \\
\text { perceived } \\
\text { fatigue }\end{array}$ & 9 & $0-90$ & $\begin{array}{c}0-3 \text { no/mild fatigue } \\
4-7 \text { moderate } \\
>7 \text { severe }\end{array}$ \\
\hline RAND MOS Social Support Scale [31] & $\begin{array}{l}\text { Social } \\
\text { Support }\end{array}$ & 19 & $0-5$ & $<4$ \\
\hline
\end{tabular}

plies the GA in non-geriatric wards, one meta-analysis could not show significant improvement in the outcome of the patients. However, the main reason for this was the low adherence rate to the geriatric team's recommendations [40]. In turn, joint geriatric and specialized care on the ward is gaining in popularity and showing promising results in more and more studies [41].

In conclusion, all physicians treating older patients with cancer should include some form of geriatric assessment in their clinical practise. Multiple organizations including the International Society of Geriatric Oncology, the National Comprehensive Cancer Network and the European Organization for the Research and Treatment of Cancer recommend the use of the GA prior to the initiation of cancer treatment. However, it is still not routinely performed due to a false belief in its complexity and time consumption. Various forms of the GA allow its incorporation in busy clinical settings. The use of a given tool and cut-off is, in light of current research results, not as important as the incorporation of the following domains: functional status, mobility/falls, cognition function, depression/anxiety, comorbidities, polypharmacy, nutritional status and social support. The more domains included, the more adequate the risk assessment that will be achieved.

Table II. CARG and CRASH score

\begin{tabular}{|c|c|c|c|c|c|}
\hline \multicolumn{2}{|l|}{ CARG score (Cancer and Aging Research Group) } & \multicolumn{4}{|c|}{ CRASH (Chemiotherapy Risk Assessment Scale for High-Age Patients) } \\
\hline \multirow[t]{2}{*}{ Variable } & \multirow[t]{2}{*}{ Score } & \multirow[t]{2}{*}{ Variable } & \multicolumn{3}{|c|}{ Points } \\
\hline & & & 0 & 1 & 2 \\
\hline \multirow{15}{*}{$\begin{array}{l}\text { - } \quad \text { Age } \geq 72 \text { years old } \\
\text { - } \quad \text { Cancer type (gastrointestinal or genitourinary) } \\
\text { - } \quad \text { Chemiotherapy dosing (standard dosing) } \\
\text { - } \quad \text { Number of chemiotherapy drugs (polychemitherapy) } \\
\text { - } \quad \text { Hemoglobin ( }<11 \mathrm{~g} / \mathrm{dL} \text { in males, } 10 \mathrm{~g} / \mathrm{dL} \text { in females) } \\
\text { - } \quad \text { Creatinine clearance }(<34 \mathrm{~mL} / \mathrm{min}) \\
\text { - } \quad \text { Hearing (fair or worse) } \\
\text { - } \quad \text { Number of falls in the past } 6 \text { months (one or more) } \\
\text { - } \quad \text { Take medications with some help/ unable } \\
\text { - } \quad \text { Walking one block, somewhat limited/ limited a lot } \\
\text { - Decreased social activity because of physical/ } \\
\quad \text { emotional health problem (limited at least sometimes) }\end{array}$} & 2 & Hematologic score & & & \\
\hline & 2 & Diastolic BP & $\leq 72$ & $>72$ & $>459$ \\
\hline & 2 & & & & \\
\hline & 2 & IADL & $26-29$ & $10-25$ & $>0.57$ \\
\hline & & & & & \\
\hline & 3 & LDH & $0-459$ & & \\
\hline & 3 & & & & \\
\hline & 2 & Chemotox & $0-0.044$ & $0.45-0.57$ & \\
\hline & 3 & & & & \\
\hline & 1 & Nonhematologic score & & & \\
\hline & 2 & & & & \\
\hline & 1 & ECOG PS & 0 & $1-2$ & $3-4$ \\
\hline & & MMS & 30 & & $<30$ \\
\hline & & MNA & $28-30$ & & $<28$ \\
\hline & & Chemotox & 0.0 .44 & $0.45-0.57$ & $>0.57$ \\
\hline
\end{tabular}

BP - blood pressure, Chemotox - toxicity of the chemotherapy regimen, ECOG PS - Eastern Cooperative Oncology Group performance status, IADL - Instrumental Activities of Daily Living, LDH - lactate dehydrogenase, MMS - Mini Mental Health Status, MNA - Mini Nutritional Assessment 
Frailty screening tools (the topic of one of the next articles) are useful. These are simple and quick tools to identify fit older patients who do not require additional assessments or interventions. However, in the case of older patients with cancer, qualified for abdominal surgery, recognised as high-risk surgery, their predictive value, as the only assessment tool, is currently insufficient.

The arguments raised about the time-consuming nature of the GA/CGA are absurd, particularly when one considers the time and resources required to treat complications. Therefore, understanding the health status of an older patient with cancer should be as important as cancer staging and tumour biology.

\section{Conflict of interest: none declared}

\author{
Jakub Kenig \\ Jagiellonian University Medical College \\ Department of General, Oncologic and Geriatric Surgery \\ ul. Prądnicka 35-37 \\ 31-202 Kraków, Poland \\ e-mail:jkenig@cm-uj.krakow.pl
}

Received and accepted: 19 May 2020

\section{References}

1. Loh KP, Soto-Perez-de-Celis E, Hsu T, et al. What Every Oncologist Should Know About Geriatric Assessment for Older Patients With Cancer: Young International Society of Geriatric Oncology Position Paper. J Oncol Pract. 2018; 14(2): 85-94, doi: 10.1200/JOP.2017.026435, indexed in Pubmed: 29436306.

2. Klabunde CN, Ambs A, Keating NL, et al. The role of primary care physicians in cancer care. J Gen Intern Med. 2009; 24(9): 1029-1036, doi: 10.1007/s11606-009-1058-x, indexed in Pubmed: 19597893.

3. Hurria A, Mohile S, Gajra A, et al. Validation of a Prediction Tool for Chemotherapy Toxicity in Older Adults With Cancer. J Clin Oncol. 2016; 34(20): 2366-2371, doi: 10.1200/JCO.2015.65.4327, indexed in Pubmed: 27185838

4. Wildiers $\mathrm{H}$, Heeren $\mathrm{P}, \mathrm{Puts} \mathrm{M}$, et al. International Society of Geriatric Oncology consensus on geriatric assessment in older patients with cancer. J Clin Oncol. 2014; 32(24): 2595-2603, doi: 10.1200/JCO.2013.54.8347, indexed in Pubmed: 25071125.

5. Balducci L, Beghe C. The application of the principles of geriatrics to the management of the older person with cancer. Crit Rev Oncol Hematol. 2000; 35(3): 147-154, doi: 10.1016/s1040-8428(00)00089-5, indexed in Pubmed: 10960797.

6. Kenis $C$, Bron D, Libert $Y$, et al. Relevance of a systematic geriatric screening and assessment in older patients with cancer: results of a prospective multicentric study. Ann Oncol. 2013; 24(5): 1306-1312, doi: 10.1093/annonc/mds619, indexed in Pubmed: 23293115.

7. Repetto L. Comprehensive Geriatric Assessment Adds Information to Eastern Cooperative Oncology Group Performance Status in Elderly Cancer Patients: An Italian Group for Geriatric Oncology Study. Journal of Clinical Oncology. 2002; 20(2): 494-502, doi: 10.1200/jco.20.2.494.

8. Hamaker ME, Schiphorst AH, ten Bokkel Huinink D, et al. The effect of a geriatric evaluation on treatment decisions for older cancer patients--a systematic review. Acta Oncol. 2014; 53(3): 289-296, doi: 10.3109/0284186X.2013.840741, indexed in Pubmed: 24134505.

9. Decoster L, Kenis C, Van Puyvelde K, et al. The influence of clinical assessment (including age) and geriatric assessment on treatment decisions in older patients with cancer. J Geriatr Oncol. 2013; 4(3): 235-241, doi: 10.1016/j.jgo.2013.04.010, indexed in Pubmed: 24070461.

10. Girre V, Falcou MC, Gisselbrecht M, et al. Does a geriatric oncology consultation modify the cancer treatment plan for elderly patients? J Gerontol A Biol Sci Med Sci. 2008; 63(7): 724-730, doi: 10.1093/gerona/63.7.724, indexed in Pubmed: 18693227.

11. Chaïbi $\mathrm{P}$, Magné $\mathrm{N}$, Breton $\mathrm{S}$, et al. Influence of geriatric consultation with comprehensive geriatric assessment on final therapeutic decision in elderly cancer patients. Crit Rev Oncol Hematol. 2011; 79(3): 302-307, doi: 10.1016/j.critrevonc.2010.08.004, indexed in Pubmed: 20888781.

12. Kalsi T, Babic-IIlman G, Ross PJ, et al. The impact of comprehensive geriatric assessment interventions on tolerance to chemotherapy in older people. Br J Cancer. 2015; 112(9): 1435-1444, doi: 10.1038/ bjc.2015.120, indexed in Pubmed: 25871332.

13. Mohile SG, Epstein RM, Hurria A, et al. Communication With Older Patients With Cancer Using Geriatric Assessment: A Cluster-Randomized Clinical Trial From the National Cancer Institute Community Oncology Research Program. JAMA Oncol. 2019 [Epub ahead of print]: 1-9, doi: 10.1001/jamaoncol.2019.4728, indexed in Pubmed: 31697365.

14. Wildiers $\mathrm{H}$, Heeren $\mathrm{P}$, Puts $\mathrm{M}$, et al. International Society of Geriatric Oncology consensus on geriatric assessment in older patients with cancer. J Clin Oncol. 2014; 32(24): 2595-2603, doi: 10.1200/JCO.2013.54.8347, indexed in Pubmed: 25071125.

15. Katz S, Akpom C. A Measure of Primary Sociobiological Functions. Int J Health Serv. 1995; 6(3): 493-508, doi: 10.2190/uurl-2ryu-wryd-ey3k.

16. Lawton MP, Brody EM. Assessment of older people: self-maintaining and instrumental activities of daily living. Gerontologist. 1969; 9(3): 179-186, indexed in Pubmed: 5349366.

17. Pfeiffer E. Multidimensional functional assessment: The OARS methodology., Durham 1975.

18. MAHONEY FI, BARTHEL DW. FUNCTIONAL EVALUATION:THE BARTHEL INDEX. Md State Med J. 1965; 14: 61-65, indexed in Pubmed: 14258950.

19. Podsiadlo D, Richardson S. The timed "Up \& Go": a test of basic functional mobility for frail elderly persons. J Am Geriatr Soc. 1991;39(2): 142-148, doi: 10.1111/j.1532-5415.1991.tb01616.x, indexed in Pubmed: 1991946.

20. Bohannon RW. Reference values for the timed up and go test: a descriptive meta-analysis. J Geriatr Phys Ther. 2006; 29(2): 64-68, doi: 10.1519/00139143-200608000-00004, indexed in Pubmed: 16914068.

21. Charlson ME, Pompei $\mathrm{P}$, Ales $\mathrm{KL}$, et al. A new method of classifying prognostic comorbidity in longitudinal studies: development and validation. J Chronic Dis. 1987; 40(5): 373-383, doi: 10.1016/00219681(87)90171-8, indexed in Pubmed: 3558716.

22. Miller MD, Towers A. A. A manual of guidelines for scoring: The cumulative Illness Rating Score for Geriatrics. 1991.

23. Brink TL, Yesavage J, Lum O, et al. Screening Tests for Geriatric Depression. Clin Gerontol. 2008; 1(1): 37-43, doi: 10.1300/j018v01n01_06.

24. Folstein M, Folstein S, McHugh P. Mini-mental state. A practical method for grading the cognitive state of patients for the clinician. J Psychiatr Res. 1975; 12(3): 189-198, doi: 10.1016/0022-3956(75)90026-6.

25. Loh KP, Pandya C, Zittel J, et al. Associations of sleep disturbance with physical function and cognition in older adults with cancer. Support Care Cancer. 2017; 25(10):3161-3169, doi: 10.1007/s00520-017-3724-6, indexed in Pubmed: 28455547.

26. Blessed G, Tomlinson BE, Roth M. The association between quantitative measures of dementia and of senile change in the cerebral grey matter of elderly subjects. Br J Psychiatry. 1968; 114(512): 797-811, doi: 10.1192/bjp.114.512.797, indexed in Pubmed: 5662937.

27. Ball LJ, Bisher GB, Birge SJ. A simple test of central processing speed: an extension of the Short Blessed Test. J Am Geriatr Soc. 1999; 47(11): 1359-1363, doi: 10.1111/j.1532-5415.1999.tb07440.x, indexed in Pubmed: 10573448.

28. Watson YI, Arfken CL, Birge SJ. Clock completion: an objective screening test for dementia. J Am Geriatr Soc. 1993; 41(11): 1235-1240, doi: 10.1111/j.1532-5415.1993.tb07308.x, indexed in Pubmed: 8227899.

29. Guigoz Y, et al. Mini Nutritional Assessment: a practical assessment tool or grading the nutritional state of elderly patients. Facts and Research in Gerontology. 1994; 2: 15-59.

30. Mendoza TR, Wang XS, Cleeland CS, et al. The rapid assessment of fatigue severity in cancer patients: use of the Brief Fatigue Inventory. Cancer. 1999; 85(5): 1186-1196, doi: 10.1002/(sici)1097-0142(19990301)85:5<1186::aid-cncr24>3.0.co;2-n, indexed in Pubmed: 10091805.

31. Sherbourne CD, Stewart AL. The MOS social support survey. Soc Sci Med. 1991; 32(6): 705-714, doi: 10.1016/0277-9536(91)90150-b, indexed in Pubmed: 2035047.

32. Kenig J, Olszewska U, Zychiewicz B, et al. Cumulative deficit model of geriatric assessment to predict the postoperative outcomes of older patients with solid abdominal cancer. J Geriatr Oncol. 2015; 6(5): 370-379, doi: 10.1016/j.jgo.2015.03.004, indexed in Pubmed: 26144556.

33. Hurria A, Togawa K, Mohile SG, et al. Predicting chemotherapy toxicity in older adults with cancer: a prospective multicenter study. J Clin Oncol. 2011; 29(25): 3457-3465, doi: 10.1200/JCO.2011.34.7625, indexed in Pubmed: 21810685. 
34. Extermann M, Boler I, Reich RR, et al. Predicting the risk of chemotherapy toxicity in older patients: the Chemotherapy Risk Assessment Scale for High-Age Patients (CRASH) score. Cancer. 2012; 118(13): 3377-3386, doi: 10.1002/cncr.26646, indexed in Pubmed: 22072065.

35. Corre R, Greillier L, Le Caër H, et al. Use of a Comprehensive Geriatric Assessment for the Management of Elderly Patients With Advanced Non-Small-Cell Lung Cancer: The Phase III Randomized ESOGIA-GFPC-GECP 08-02 Study. J Clin Oncol. 2016; 34(13): 1476-1483, doi: 10.1200/ JCO.2015.63.5839, indexed in Pubmed: 26884557.

36. Spyropoulou D, Pallis AG, Leotsinidis $M$, et al. Completion of radiotherapy is associated with the Vulnerable Elders Survey-13 score in elderly patients with cancer. J Geriatr Oncol. 2014; 5(1): 20-25, doi: 10.1016/j. jgo.2013.08.002, indexed in Pubmed: 24484714.

37. Ellis G, Langhorne P. Comprehensive geriatric assessment for older hospital patients. Br Med Bull. 2004; 71: 45-59, doi: 10.1093/bmb/ Idh033, indexed in Pubmed: 15684245.

38. Baztán JJ, Suárez-García FM, López-Arrieta J, et al. Effectiveness of acute geriatric units on functional decline, living at home, and case fatality among older patients admitted to hospital for acute medical disorders: meta-analysis. BMJ. 2009; 338: b50, doi: 10.1136/bmj.b50, indexed in Pubmed: 19164393.

39. Ellis $G$, Whitehead MA, Robinson D, et al. Comprehensive geriatric assessment for older adults admitted to hospital: meta-analysis of randomised controlled trials. BMJ. 2011; 343: d6553, doi: 10.1136/bmj. d6553, indexed in Pubmed: 22034146.

40. Deschodt M, Flamaing J, Haentjens $\mathrm{P}$, et al. Impact of geriatric consultation teams on clinical outcome in acute hospitals: a systematic review and meta-analysis. BMC Med. 2013; 11:48, doi: 10.1186/1741-7015-1148, indexed in Pubmed: 23433471.

41. González-Montalvo Jl, Alarcón T, Mauleón JL, et al. The orthogeriatric unit for acute patients: a new model of care that improves efficiency in the management of patients with hip fracture. Hip Int. 2010; 20(2): 229-235, doi: 10.1177/112070001002000214, indexed in Pubmed: 20544649. 